\title{
Correction to: Encapsulation of phase change materials with alginate modified by nanostructured sodium carbonate and silicate
}

\author{
Raouia Miloudi $^{1} \cdot$ Djamal Zerrouki $^{1} \mathbb{D}$
}

Published online: 18 May 2020

C Iran Polymer and Petrochemical Institute 2020

\section{Correction to: Iranian Polymer Journal \\ https://doi.org/10.1007/s13726-020-00819-3}

The article listed above was initially published with typo error in first author name. First author name corrected in original article.

The original article can be found online at https://doi.org/10.1007/ s13726-020-00819-3.

Djamal Zerrouki

djamal.zerrouki@gmail.com

1 Laboratoire de Dynamique Interaction et Réactivités Des Systèmes, Faculté des Sciences Appliquées, Université Kasdi Merbah Ouargla, Route de Ghardaïa, BP 511, 30000 Ouargla, Algeria 